\title{
Benign Adrenal Gland Composite Pheochromocytoma
}

National Cancer Institute

\section{Source}

National Cancer Institute. Benign Adrenal Gland Composite Pheochromocytoma. NCl Thesaurus. Code C92181.

A composite pheochromocytoma that is confined to the adrenal gland and does not have any metastatic potential. 